\title{
THERMOGRAPHIC SKIN EVALUATION AFTER THE USE OF ELECTROSURGICAL DEVICES AND SCALPEL MADE INCISIONS IN RABBITS
}

\author{
Linda Gatiņa, Agris Ilgažs, Dace Bērziṇa \\ Latvia University of Life Science and Technologies, Latvia \\ linda.gatina@inbox.lv
}

\begin{abstract}
The purpose of using electrosurgical devices in veterinary practice is to reduce bleeding during the cut increasing temperature locally, causing coagulation and apoptosis of proteins. There is a lack of data on the extent and depth of these thermal damages and whether these effects on the different tissues are the same. Because of that, the aim of this study was to investigate which of the different electrosurgical devices causes highest heating effect on the skin tissue of rabbits (Oryctolagus cuniculus). The research was carried out at the Latvia University of Life Sciences and Technologies, Faculty of Veterinary Medicine. It included 50 rabbits, on average 2 years old, clinically healthy, with similar weight and condition. We formed five experimental groups: skin tissue cut with $\mathrm{CO}_{2}$ laser $(\mathrm{n}=10)$, an electrocoagulator $(n=10)$, a tissue welding device $(n=10)$, a radiofrequency apparatus $(n=10)$ and a scalpel as control group $(\mathrm{n}=10)$. In order to evaluate the thermal effects of electrosurgical instruments on tissues, we performed contactless thermography. There were taken 3 images for each animal, totally 150 skin thermo-gramms. From the obtained results we conclude that the most pronounced thermal effect on rabbit's skin was caused with laser and an electrocoagulator. All electrosurgical devices caused a significantly higher $(p<0.01)$ increase in skin temperature compared to a surgical scalpel at the moment of tissue incision. During the study, it was found that the gentlest electrosurgical devices used on rabbit skin tissue was a radiofrequency device.
\end{abstract}

Key words: Laser, electrocoagulator, tissue welding device, radiofrequency.

\section{Introduction}

For centuries, doctors and scientists have been trying to find the most effective and at the same time the gentlest type of tissue incision that would provide a qualitative surgeon's work during surgery, while reducing the amount of tissue damage, the frequency of complications and the tissue healing period. Classical surgical scalpels do not always meet the requirements of modern veterinary medicine. This is why other types of tissue incision, known and approbated in human medicine, are becoming more common in veterinary practice. Various electrosurgical devices mentioned in the literature were widely introduced in human medicine only at the beginning of this century and still are considered to be an integral part of modern surgery worldwide (Vogt, 2008; Taheri et al., 2014).

Electrosurgery is conducting of the high frequency current through tissue to achieve a specific surgical effect. Heat generation and thermal tissue damage are the cause of the obtained electrosurgery effect. The only variable that determines the ultimate current effect on the tissue is the depth of affected tissue and the rate of heating (Taheri et al., 2014; Haneke, 2015).

In veterinary medicine, the most frequent purpose of using electrosurgical devices is to cut tissue during surgical manipulations and to reduce bleeding, causing coagulation. The ability of these electrical devices is to interrupt tissue interactions incising them in the place of the most intense impact, as well as the ability to act on them thermally, causing protein coagulation. Some electro-surgical biophysical mechanisms are more or less studied, but the full effect of these technologies on different tissues is unknown. It has been investigated that during their exposure to tissues, the temperature increases locally, causing coagulation and apoptosis of proteins (Tobias \& Johnston, 2012; Haneke, 2015), but there is a lack of data on the extent and depth of these thermal damages. It is also not known whether these effects on the different tissues of the body are the same and how they affect the regeneration processes.

In human medicine are studies with different electrosurgical devices where thermal effect on the skin is investigated using thermographic examination. Schneider and co-authors have investigated ultrasonic scalpels and monopolar electrocautery thermal effect on the skin of neck. The main conclusion was thermographic examination. Schneider and co-authors have investigated ultrasonic is superior to monopolar electrocautery for skin incisions in neck dissection (Schneider et al., 2018)

There are different electrosurgical devices such as electrocoagulator, laser, tissue welding and radio frequency devices. Tissue incision by electrocoagulator is achieved by heating the tissue to the boiling point, causes a rapid explosion of water in the cell and protein denaturation, which leads to cutting the tissue (Wall \& Gertners, 2008; Taheri et al., 2014). Thermal effect of electrocoagulator on the tissue depends on the energy level, the duration of application and the biological properties of the tissues (Beriat et al., 2012; Tobias \& Johnston, 2012; Haneke, 2015).

Laser impact is based on the emission of photons. Photon is the basic unit of light and electromagnetic radiation. Two types of photon emissions are distinguished - spontaneous (eg. sunlight) and stimulated. Stimulated photons emit monochromatic and synchronous light waves - lasers (Wall \& Gertners, 2008). Laser causes thermal damage, 
necrosis and carbonization not only on the damaged bone tissue, but also on the surrounding soft tissues (Saeed \& Mahmood, 2011).

The hypothesis about the effect of the tissue welding device is based on the denaturation of the albumin, collagen and elastin in the walls of the blood vessels. Tissue cells are exposed to the electrical current and incised. (Патон, 2011; Tobias \& Johnston, 2012). Using a tissue welding device, the tissue surface can reach up to $+100{ }^{\circ} \mathrm{C}$ high temperature and the surrounding tissue is traumatized at a distance of $1 \mathrm{~mm}$ from the cutting site. D. Eberli and his coauthors during prostatectomy surgery found that surrounding tissues were heated to $+75-85^{\circ} \mathrm{C}$ The tissue at a distance of $1.7 \mathrm{~mm}$ to $2.7 \mathrm{~mm}$ from the wound is heated to almost $+45{ }^{\circ} \mathrm{C}$, which is critical and it causes thermal injury in the tissue (Eberli et al., 2009; Tobias \& Johnston, 2012).

The basic principles of the radio frequency device are significantly different from other electronic devices. During exposure to radio frequency device, the tissue becomes an object which radio waves flow through. By using radio frequency current, the temperature of the internal structures of the cells increases, intracellular fluid is lost and protein denaturation occurs (Tobias \& Johnston, 2012; Haneke, 2015) The narrow range of radio frequency waves ensures reduced heating of surrounding tissues (Vogt, 2008; Taheri et al., 2014). Radio waves during surgical manipulation can almost completely prevent thermal damage (Haneke, 2015).

Overall thermal damage occurs when the heat is applied to the tissues faster than they are able to absorb and disperse it. The severity of the damage depends on the temperature of the heat source, the conductivity of the tissues and the duration of contact. Temperatures above $+45{ }^{\circ} \mathrm{C}$ can cause coagulation necrosis and irreversible skin damage. There is a transition zone around the burn site where the damage is potentially reversible. Around it is hyperaemia, where tissue damage is minimal and healing processes occur (Beriat et al., 2012; Pereira et al., 2012).

Based on the lack of information on the thermal effects of electrosurgical devices, the aim of this research was to investigate which of the different electrosurgical devices caused the highest heating effect on the skin tissue in rabbits (Oryctolagus cuniculus).

\section{Materials and Methods}

The research was carried out at the Faculty of Veterinary Medicine, Latvia University of Life Sciences and Technologies. An experiment started in 2015 and was completed in 2018. It included 50 rabbits, on average 2 years old, clinically healthy, with similar weight (about $3.5 \mathrm{~kg}$ ) and condition. We formed five experimental groups of animals, whose skin incision was made by $\mathrm{CO}_{2}$ laser 'Aesculight' $(\mathrm{n}=10)$, an electrocoagulator 'EK-300M1 MAC' $(\mathrm{n}=10)$, a tissue welding device 'BOVA ARC 250' $(\mathrm{n}=10)$ and a radiofrequency apparatus $(\mathrm{n}=10)$, as well as a control group $(n=10)$ where the incision was made by a scalpel. We have received permit from the Food and Veterinary Service to work with experimental animals (No 75).

In the state of general anaesthesia, during surgery a skin incision was made by one of each instruments included in this study according to group of rabbits. To avoid discomfort during surgery, first anaesthesia was injected intramusculary. As soon as the animal reached the sleep state, it was connected to the inhalation anaesthesia device and monitoring sensors. At the beginning of the operation, analgesic medicament was injected intramuscularly with 24-hour effect. The reinjection of analgesics and antibiotics was evaluated by animal behaviour and physiological parameters.

In order to evaluate the thermal effects of electrosurgical instruments on tissues, we performed contactless thermography with the Flir-i3 thermograph during exposure. The temperature range checked by thermograph is $-20{ }^{\circ} \mathrm{C}$ to $+300{ }^{\circ} \mathrm{C}$. During the surgery thermography was performed by placing the thermograph at a distance of $7 \mathrm{~cm}$ from the cut site; 3 images were taken for each animal, totally 150 skin thermos-gramms. The thermographic changes of obtained images were analysed using a special computer program 'FLIR QuicReport 1.2 SP2', which allows analysis to be performed within $\pm 0.01{ }^{\circ} \mathrm{C}$ error.

Statistical analysis of the obtained temperature indicators was performed with the help of program Excel2016, calculating the mean, standard deviation, minimal value and maximal value for each group. In the result section standard deviation is marked using \pm symbol. In order to evaluate the differences in the average temperature of the groups, we used the Student's t-test with $\alpha=0.05$.

\section{Results and Discussion}

Thermography was performed to evaluate heating effect of the skin during exposure to assess and compare data of each surgical electrical device. There were obtained 30 thermo-gramms for each study group, totally 150 images.

The analysis of the obtained thermos-gramms showed that the use of laser caused the highest thermal effect, which reached a maximum of $+255.7^{\circ} \mathrm{C}$ and was not lower than $+197.1^{\circ} \mathrm{C}$. According to the use of electrocoagulator, we found that in the site of skin incisions there was also a very high temperature above $+130{ }^{\circ} \mathrm{C}$ in some measurements. Regarding other electrical devices used in this research, the tissue heating above $+100^{\circ} \mathrm{C}$ (which is known to be a boiling temperature) was not detected in both, during the use 
Table 1

Thermal values $\left({ }^{\circ} \mathrm{C}\right)$ of skin during incision with different electrical devices and surgical scalpel

\begin{tabular}{|l|l|l|l|l|}
\hline \multicolumn{1}{|c|}{ Electrosurgical devices } & \multicolumn{1}{c|}{ Mean } & \multicolumn{1}{c|}{ Standard deviation } & \multicolumn{1}{c|}{ Minimal Value } & \multicolumn{1}{c|}{ Maximal value } \\
\hline Laser & 255.7 & 18.34 & 197.1 & 270.2 \\
\hline Radio frequency devices & 57.5 & 16.83 & 38.3 & 93.0 \\
\hline Electrocoagulator & 93.5 & 29.76 & 36.3 & 136.2 \\
\hline Tissue welding device & 66.2 & 11.59 & 41.3 & 86.8 \\
\hline Surgical scalpel & 35.4 & 1.15 & 33.0 & 37.6 \\
\hline
\end{tabular}

\section{Comparison of tissue temperature data after the use of different electrosurgical} device with Student's t-test

\begin{tabular}{|l|l|l|}
\hline \multicolumn{2}{|c|}{ Electrosurgical devices } & \multicolumn{1}{c|}{ p-values } \\
\hline \multirow{4}{*}{ Laser } & Radio frequency device & $5.049 \times 10^{-46}$ \\
\cline { 2 - 3 } & Electrocoagulator & $1.395 \times 10^{-29}$ \\
\cline { 2 - 3 } & Tissue welding device & $8.943 \times 10^{-43}$ \\
\cline { 2 - 3 } & Surgical scalpel & $2.709 \times 10^{-33}$ \\
\hline \multirow{4}{*}{ Radio frequency device } & Electrocoagulator & $6.594 \times 10^{-7}$ \\
\cline { 2 - 3 } & Tissue welding device & 0.024 \\
\cline { 2 - 3 } & Surgical scalpel & $6.263 \times 10^{-8}$ \\
\hline \multirow{2}{*}{ Electrocoagulator } & Tissue welding device & $3.608 \times 10^{-5}$ \\
\cline { 2 - 3 } & Surgical scalpel & $1.381 \times 10^{-11}$ \\
\hline Tissue welding device & Surgical scalpel & $5.868 \times 10^{-15}$ \\
\hline
\end{tabular}

of radio frequency devices (maximal value $+93{ }^{\circ} \mathrm{C}$ ) and the tissue welding device $\left(+86.8^{\circ} \mathrm{C}\right)$. From all of the electrosurgery devices the radiofrequency device had the lowest thermal effect $\left(57.5 \pm 16.83^{\circ} \mathrm{C}\right)$ on the skin tissue. In the control group, the skin tissue was not heated at all. We found that the upper surface temperature of the skin when it was incised by scalpel was $+35.4^{\circ} \mathrm{C}$ or even slightly below the physiological limit $\left(+33^{\circ} \mathrm{C}\right)$. Such a slight drop in temperature can be explained by the preparation procedure of the surgery area.

Generally, all electrosurgical devices heated the tissues above $+45{ }^{\circ} \mathrm{C}$. According to other authors research results, this is the limit value of thermal critical point of tissue trauma (Tobias \& Johnston, 2012). We found out that the widest range of temperature changes were obtained after the incisions made with electrocoagulator, where the average values fluctuating within almost $+30{ }^{\circ} \mathrm{C}$. This can be explained because of basic operating principles of these devices, as a rapid increase in temperature above $+100{ }^{\circ} \mathrm{C}$ is achieved. Adjacent cells are minimally affected if heating reaches up to a limit of $+100{ }^{\circ} \mathrm{C}$. However, protein coagulation and subsequent coagulation necrosis cannot be excluded if the temperature may exceed $+45^{\circ} \mathrm{C}$. The average values of the temperature changes caused by the radio frequency devices $\left(57.5 \pm 16.83{ }^{\circ} \mathrm{C}\right)$ and the tissue welding device $\left(66.2 \pm 11.59{ }^{\circ} \mathrm{C}\right)$ also shows that we can expect coagulation necrosis in further tissue examination (Tobias \& Johnston, 2012).

During the study, it was also important to compare which of the electrosurgical devices heats the tissue significantly more than others. Among all electrosurgical devices, the laser caused the greatest increase in temperature during tissue incision, which proved to be significant $(\mathrm{p}<0.01)$ compared with other devices. Changes in temperature during tissue incision also differed significantly between tissue welding device and electrocoagulator $\left(\mathrm{p}=3.608 \times 10^{-5}\right)$. When using electrocoagulator, the heating effect on the skin was significantly higher. The difference in temperature changes between the radio frequency devices and the tissue welding device was significant, but with a lowes $p$-value $(\mathrm{p}=0.024)$. The gentlest electrosurgical devices used on rabbit skin tissue was a radio frequency device that had the lowest heating effect on the tissues, average $57.5 \pm 16.83^{\circ} \mathrm{C}$. Though making a tissue incision by scalpel, the wound temperature was significantly lower $(\mathrm{p}<0.01)$ than performing the same procedure by electrosurgical device.

Most authors in their studies had described thermal changes in tissue caused by the use of electrosurgical devices (Eberli et al., 2009; Saeed \& Mahmood, 
2011; Tobias \& Johnston, 2012). Our study shows that various electrosurgical devices have a significant thermal effect on tissues that can cause pathological thermal skin damage, which encourages for future investigation according to tissue morphological changes caused by different electrosurgical devices.

\section{Conclusions}

1. The highest thermal effect on the rabbit skin during surgical incisions was caused using a laser (up to $\left.+270.2^{\circ} \mathrm{C}\right)$ and an electrocoagulant $\left(+136.2^{\circ} \mathrm{C}\right)$.
2. All electrosurgical devices caused a significantly higher $(p<0.01)$ increase in skin temperature compared to a surgical scalpel at the time of tissue incision.

3. During the study, it was found that the gentlest electrosurgical devices used on rabbit skin tissue was a radio frequency device that had the lowest heating effect on the tissues, average $57.5 \pm 16.83{ }^{\circ} \mathrm{C}$.

\section{References}

1. Beriat, G.K., Akmansu, S.H., Ezerasla, H., Dogana, C., Han, U., Saglam, M., Senel, O.O., \& Kocaturk, S. (2012). Comparison of thermal tissue injuries caused by ultrasonic scalpel and electrocautery use in rabbit tongue tissue. Journal of Basic Medical Sciences. 12(3), 151-157. DOI: 10.17305/bjbms.2012.2462.

2. Eberli, D., Hefermehl, L.J., Sulser, T., \& Knönagel, H. (2009). Lateral temperature spread of vessel-sealing devices: are they safe for nerve sparing radical prostatectomy The Journal of Urology, Vol. 181(4), 720. DOI: 10.1016/S1569-9056(09)60410-3.

3. Haneke, E. (2015). Electrosurgery. In A. Katsambas, T. Lotti, C. Dessinioti \& A.M. D’Erme (Eds.), European Handbook of Dermatological Treatments (pp. 1179-1182). Springer-Verlag Berlin Heidelberg

4. Pereira, D.S.T., Lima-Ribeiro, M.H.M., Pontes-Filho, N.T., Carneiro-Lea, A.M.A., \& Correia1, M.T.S. (2012). Development of Animal Model for Studying Deep Second-Degree Thermal Burns. Journal of Biomedicine and Biotechnology. Vol. 1, 7. ID 460841.

5. Saeed, K.A., \& Mahmood, I.I. (2011). Healing of Nd:YAG laser incision in tongue of rabbits compared with scalpel incision, an experimental study. JSMC, Vol. 1, No. 1, pp. 38-43.

6. Schneider, D., Goppold, K., Kaemmerer, P.W., Schoen, G., Woehlke, M., \& Bschorer, R. (2018). Use of ultrasonic scalpel and monopolar electrocautery for skin incisions in neck dissection: a prospective randomized trial. Oral and Maxillofacial Surgery. 22(2), 169-175. DOI: 10.1007/s10006-018-0686.

7. Taheri, A., Mansoori, P., Sandoval, L.F., Feldman, S.R., Pearce, D., \& Williford, P.M. (2014). Basics and principles. In Electrosurgery Part I. Journal of the American Academy of Dermatology. Vol. 70(4), 591-591. DOI: 10.1016/j.jaad.2013.09.056.

8. Tobias, K.M., \& Johnston, S.A. (2012). Surgical Modalities: Laser, Radiofrequency, Ultrasonic, and Electrosurgery. In S. Stringer (Eds.), Veterinary surgery small animals (pp. 180-186). Elsevier Inc.

9. Vogt, K. (2008). RADIOFREQUENCY Surgery in Otorhinolaryngology. 1 ed. Tuttlingen: Endo Press

10. Wall, J., \& Gertners, M. (2008). Energy transfer in the practice of surgery. In Norton J.A., Barie P.S., Bollenger R.R., et al., editors: Surgery: basic science and clinical evidence, 2 ed., p. 2345. New York, Springer Science

11. Патон, Б.Е. (2011). Сварка живых мягких тканей (Live soft tissue welding). 8, Академия наук Украины, Украина. (in Russian) 